\title{
Tardive Dyskinesia in Older Persons Taking Antipsychotics
}

\section{Leslie Citrome $\mathbb{D}^{1}$ \\ Stuart H Isaacson ${ }^{2}$ \\ Danielle Larson ${ }^{3}$ \\ Daniel Kremens ${ }^{4}$}

'New York Medical College, Valhalla, NY, USA; 'Parkinson's Disease and Movement Disorders Center of Boca Raton, Boca Raton, FL, USA; ${ }^{3}$ Parkinson's Disease and Movement Disorders Center, Northwestern University Feinberg School of Medicine, Chicago, IL, USA ${ }^{4}$ Department of Neurology, Jefferson Comprehensive Parkinson's Disease and Movement Disorders Center, Thomas Jefferson University, Philadelphia, PA, USA
Correspondence: Leslie Citrome New York Medical College, 40 Sunshine Cottage Road, Valhalla, NY, I0595, USA $\mathrm{Tel}+$ I 845 362-208I

Email citrome@cnsconsultant.com

\begin{abstract}
Tardive dyskinesia (TD) is a hyperkinetic movement disorder caused by the use of dopamine receptor-blocking agents (DRBAs), a category of medications that includes first- and second-generation antipsychotics (APs) and agents such as metoclopramide that are used for the treatment of nausea and gastrointestinal dysmotility. While TD can affect people of all ages, older age is associated with increased risk of TD and also with the emergence of TD occurring after shorter treatment durations and lower dosages of DRBAs. TD is characterized by involuntary movements that include the face, limbs, and trunk, and is associated with increased comorbidities, social stigmatization, and impaired physical and mental health. Once present, TD tends to persist despite AP dose adjustment or discontinuation. Even with the use of US Food and Drug Administration (FDA)-approved medications for TD, symptoms may persist. Because the leading hypothesis for the pathophysiology of TD has been dysregulation of dopamine transmission due to treatment with DRBAs, APs that avoid postsynaptic dopamine receptor blockade may provide an alternative therapeutic approach for patients who require an AP. In this review, we discuss the risks, burdens, prevention, and management of TD, with a focus on older people.
\end{abstract}

Keywords: tardive dyskinesia, antipsychotic medications, age

\section{Introduction}

Tardive dyskinesia (TD) is a hyperkinetic movement disorder caused by dopamine receptor-blocking agents (DRBAs), a category of medications that includes antipsychotics (APs) and some agents used to treat nausea and gastrointestinal dysmotility, such as metoclopramide. ${ }^{1}$ The Diagnostic and Statistical Manual of Mental Disorders, 5th edition, defines TD as involuntary athetoid or choreiform movements. Symptoms must last for at least a few weeks and develop in association with the use of a neuroleptic medication for at least a few months. ${ }^{2}$ TD is often irreversible, can impact daily life, and can be socially stigmatizing. ${ }^{3}$ While all individuals treated with DRBAs are at risk for developing TD, older individuals are at higher risk and particularly vulnerable to developing this disorder, even after shorter exposure to newer second-generation APs. ${ }^{4-7}$

In addition to their US Food and Drug Administration (FDA)-approved indications, APs have also been used for non-approved (ie, "off-label") indications, including neuropsychiatric symptoms associated with Parkinson's disease or dementia. The increasing and widespread use of APs has led to more elderly people being placed at risk of TD. ${ }^{8-11}$ Moreover, older individuals on APs may face a greater risk for complications related to TD, as they are more prone to falls, orthostatic hypotension, somnolence, and generally have a greater burden of 
comorbidities than younger people. ${ }^{12-16}$ The aim of this review is to examine the risk, burden, and management of TD with a particular focus on the elderly.

\section{Overview of Tardive Dyskinesia}

TD is characterized by a delayed onset of involuntary motor movements in the face, trunk, and limbs after exposure to DRBAs. ${ }^{4,17}$ Involuntary movement are classically peri-oral, including grimacing, tongue protrusion, and lip puckering, but also include neck, shoulder, and limb movements. ${ }^{18}$ In some cases, symptoms can be severe enough to interfere with breathing, speaking, eating, and ambulation. ${ }^{19,20}$

TD is often irreversible and can impose long-lasting burdens on psychosocial, physical, and economic health., ${ }^{4-21-23}$ Historically, assumptions that those afflicted are unaware of their symptoms or unconcerned with them have obscured these burdens, especially among persons with schizophrenia who can have limited insight into their physical and mental health. ${ }^{24,25}$ However, a recent study of those with a history of AP use for the treatment of schizophrenia, schizoaffective disorder, mood disorder, and other psychiatric disorders, found that nearly $80 \%$ of subjects with a clinician-confirmed diagnosis of possible TD reported noticing recent involuntary movements. ${ }^{21}$ Many of these individuals also felt that the uncontrollable movements impacted their ability to engage in daily activities, talk, or socialize. ${ }^{21}$

The degree to which those with TD experience reduced general health, life enjoyment and satisfaction, and enhanced social withdrawal is generally proportional to the severity of the symptoms. ${ }^{3}$ The disorder can impact leisure activities or the willingness to participate in community activities. TD can also hinder the ability to find and maintain employment due to the symptoms themselves or embarrassment caused by the symptoms. ${ }^{21,26}$ The financial impact of TD on the healthcare system can be considerable, as reported in a large, retrospective analysis that found that people with both TD and schizophrenia, mood disorders, or other psychiatric disorders experience $29 \%$ more hospital admissions, 5\% more outpatient visits, and $21 \%$ more emergency room visits than those without $\mathrm{TD}^{22}$ This results in a nearly doubling of the healthcarerelated financial burden for individuals with TD from $\$ 28,777$ to $\$ 54,656$ over a 2 -year period. ${ }^{22}$

\section{Prevalence and Risk of TD}

The mean prevalence of TD in people treated with APs was $20-25 \%$ according to meta-analyses of articles published between 1959 and 2015. ${ }^{27,28}$ A 20-year longitudinal study initiated prior to the widespread use of secondgeneration APs calculated a yearly cumulative incidence of TD of $4 \%-5 \% .{ }^{27}$ The frequent occurrence of TD and acute extrapyramidal symptoms, such as drug-induced parkinsonism and acute dystonia, encouraged the development of second-generation APs, which were intended to minimize the incidence of adverse neurological effects. Although acute drug-induced parkinsonism and acute dystonia are lessened, TD has not been eliminated. The annual prevalence of TD among patients receiving APs was estimated to be 7.6 to 9.7 per 1000 people according to a large retrospective observational study of electronic health records, with nearly $80 \%$ of study participants using second-generation APs. ${ }^{15}$ A direct comparison of annualized incidence between first- and secondgeneration APs indicates a reduced but not eliminated risk of TD with use of second-generation APs (range of $0.8 \%$ to $3 \%$ with use of second-generation APs vs $5.4 \%$ to $7.7 \%$ with use of first-generation APs). ${ }^{6,29}$

The most important risk factors for the development of TD include older age and cumulative exposure to the DRBA. Other risk factors include the dopamine-receptor binding affinity of the DRBA in question, female sex, mood disorders, dementia, and prior drug-induced parkinsonism. ${ }^{4,30-33}$ Smoking and substance abuse may also be associated with a higher risk of developing TD. ${ }^{33}$

\section{TD in Older Populations}

As noted, age is a key risk factor for developing TD. ${ }^{31,34}$ A study of 404 people aged $\geq 55$ years reported cumulative TD incidences of $26 \%, 30 \%$, and $60 \%$ after the first, second, and third year, respectively, of first-generation AP use. ${ }^{35}$ This is considerably higher than that observed in younger people; a meta-analysis of 32 randomized studies that included 10,706 subjects of mixed ages calculated an annualized TD incidence of $6.5 \%$ with the use of first-generation APs. ${ }^{28}$ Second-generation APs offer older people a reduced risk of approximately $6 \%$ and $7 \%$ after the first year of use to $11 \%$ after the second year of use in those who are naïve to firstgeneration APs. However, the risk (nonetheless remains higher than the incidence of $\leq 3 \%$ observed among younger adults treated with second-generation APs. ${ }^{29,36}$ Although TD risk increases in a dose-dependent manner, older patients are susceptible after exposure to even low doses of secondgeneration APs. ${ }^{4,37}$ A study of 255 older patients with dementia (mean age: 82.5 years) found that $1.7 \%$ of patients treated daily with 0.75 to $1.5 \mathrm{mg}$ risperidone for 1 year developed TD; in contrast, no new cases of TD were reported 
in a mixed-age adult population of 541 patients treated with a mean dose of risperidone $3.9 \mathrm{mg} / \mathrm{day}$ for 6 months. ${ }^{37,38}$ Similarly, no change from baseline was observed in TD symptoms among adults aged $\leq 65$ years after 1 year of 4 to $10 \mathrm{mg}$ risperidone daily. ${ }^{39}$ The mechanism underlying agerelated increased susceptibility is unclear but may be due to higher cumulative exposure to APs as well as an age-related decrease in dopaminergic neurons in the substantia nigra. ${ }^{40}$

Because APs are sometimes used off-label for dementia-related psychosis and aggression, ${ }^{8,11}$ TD can be encountered in this population, particularly within facilities that care for older people. Up to $33 \%$ of patients residing in nursing homes or assisted living facilities receive APs, predominantly for off-label indications. ${ }^{8}$ A survey of 350,000 nursing home residents in 8 states, representing $40 \%$ of residents nationally, found that in 2006, 27.6\% of residents had taken APs in the last 7 days, and only $20.7 \%$ of these were for treatment of the primary indications of schizophrenia or bipolar disorder. ${ }^{41}$ The National Nursing Home Survey of 300,000 residents found that $23 \%$ of respondents had received at least 1 second-generation $\mathrm{AP}$, and $86.3 \%$ of these prescriptions were for off-label indications. ${ }^{42}$ Dementia is one of the most common indications for off-label AP use in these facilities, despite the bolded "black box" warning against AP use in patients with dementia-related psychosis. ${ }^{8,11}$ Behavioral issues related to dementia may in part drive AP use in this population. Crystal et al found that half of residents with dementia and aggressive behavior received AP treatment, while $40 \%$ and $23 \%$ of patients with nonaggressive dementia or dementia without behavioral symptoms, respectively, also received APs. ${ }^{41}$ Other common reasons for off-label AP use among older people are anxiety and insomnia. ${ }^{8}$ The prevalence of off-label AP use, particularly among older individuals, has prompted the Centers for Medicare and Medicaid Services to issue guidelines and fact sheets recommending against this practice, ${ }^{43}$ and long-term care settings are compelled to adhere to efforts to mitigate their use. However, recent studies suggest AP use outside of approved indications continues. $^{44,45}$

\section{Impact of TD in Older People}

The impact of TD on an individual's physical, mental, and economic health may intensify with age. ${ }^{3,22}$ The social and emotional effects of symptoms are highly debilitating for people with TD of all ages, but feelings of isolation and depression may be especially profound for older people. ${ }^{3,16}$ Older individuals are also uniquely vulnerable to the physical consequences of TD, such as impaired gait and balance, which can lead to falls. ${ }^{16,26}$ TD in older patients often presents as oro-bucco-lingual dyskinesia, and these movements can interfere with eating and swallowing; incidents of choking resulting from respiratory TD have been reported. ${ }^{7,19,46}$ Further, oro-bucco-lingual TD can cause loosening of natural and artificial teeth and be augmented by edentulousness and denture use; edentulousness itself can cause abnormal movements of the mouth in the absence of neurological disorders such as TD. ${ }^{26,46,47}$ Older patients may also be affected by dyskinesias of the limbs, trunk, and respiratory system, with symptoms such as grunting. . $^{726,48}$

The observation that older people with TD are also at increased risk of cardiac, metabolic, and other movement disorder comorbidities complicates treatment of TD in these patients. ${ }^{12-15}$ Lastly, the high healthcare utilization costs associated with TD are likely to severely tax the resources of older people on fixed or limited incomes and stress the healthcare system in general. ${ }^{22}$ Given these considerable impacts, treatment plans for older individuals with psychiatric conditions should include modification of prescribing practices to minimize the risk of TD.

\section{Mechanisms of TD with APs}

Understanding the pathophysiology of TD is essential to choosing therapies for psychiatric conditions that minimize the risk of this disorder in older patients. While there is not a universally accepted mechanism through which APs drive the development of TD, a leading hypothesis revolves around the dysregulation of dopaminergic transmission. ${ }^{49,50}$ Antagonism of postsynaptic dopamine D2 receptors in the mesolimbic pathway, specifically in the ventral striatum, drives efficacy of APs in reducing positive symptoms associated with psychosis. However, long-term blockade of D2 receptors in the nigrostriatal pathway, specifically in the dorsal striatum, can lead to an increase in the number and function of postsynaptic dopamine D2 receptors (often referred to as the "supersensitivity" or "hypersensitivity" hypothesis) subsequently interfering with voluntary motor control. $^{4,51,52}$ This enhanced sensitivity to dopamine in the dorsal striatum can lead to several types of motor symptoms, including TD. Genetic studies in support of a role for dopamine hypersensitivity in TD include observations that mutations in the PIP5K2A and DRD2 dopamine receptor genes and in the glycine variant of the 
dopamine D3 receptor have been linked to the development of TD in people with schizophrenia. ${ }^{53-55}$

Second-generation APs are thought to carry a lower risk for the development of TD compared with first-generation APs because although both types of APs are DRBAs, second-generation APs are also antagonists at presynaptic serotonin $5-\mathrm{HT}_{2 \mathrm{~A}}$ receptors, which can lessen the risk of drug-induced movement disorders in general. In addition, some second-generation APs have a lower binding affinity to the postsynaptic dopamine receptor as well. ${ }^{18,56,57}$

Investigational uses of functional magnetic resonance imaging (fMRI) to help elucidate the pathophysiology of TD are also of interest. For example, two recent reports demonstrated statistically significant differences in gray matter volume and resting state functional connectivity of motorrelated brain regions of interest in patients with schizophrenia treated with antipsychotics with and without a TD diagnosis. Gray matter volumes of the brainstem, inferior frontal and precentral gyri, cuneus, and lingual gyrus were significantly different in patients with TD than in those without. ${ }^{58}$ Similarly, patients with TD exhibited a reduction in resting state functional connectivity between the right postcentral gyrus and the inferior frontal gyrus of the left triangular part compared with patients without TD. ${ }^{59}$ Gray matter volumes of the cuneus and lingual gyrus and the reduction in resting state functional connectivity observed were also correlated with TD severity, as assessed by the total score on the Abnormal Involuntary Movement Scale, providing further support that changes in gray matter volume or functional connectivity may be related to the pathophysiology of TD. ${ }^{58,59}$ The use of fMRI in evaluating TD remains investigational, and its relevance in older populations deserves further study.

\section{Strategies for Minimizing TD Risk}

TD can be irreversible, highlighting the need for preventative strategies. Many clinicians focus primarily on limiting the use of TD-inducing medications and secondarily on detecting TD symptoms early. ${ }^{51,60,61}$ Considering the pharmacology of individual APs with an understanding of proposed TD pathophysiology informs the selection of therapies that are least likely to induce TD. Use of less potent dopamine receptor blocking second-generation APs instead of first-generation APs may reduce TD risk. Correll and colleagues presented the initial support for a lower risk of TD associated with second-generation APs compared with first-generation APs in a meta-analysis of 11 randomized studies. ${ }^{6}$ Here, the annual TD risk estimate associated with haloperidol was 5.4\% across 3 studies, whereas across 5 studies, the risk estimates associated with olanzapine, risperidone, quetiapine, or amisulpride ranged from $0.5 \%$ to $1.5 \%$. In addition, because older people both experience benefit from second-generation APs at low doses and are at greater risk of developing TD after minimal exposure, treatment regimens should reflect these sensitivities and implement the lowest effective AP dose., ${ }^{7,62}$

Several nondopaminergic approaches to treat psychosis are also in development. Serotonin receptor inhibition has not been associated with TD, and selective inverse agonism/antagonism of 5HT receptors may be a therapeutic strategy that would mitigate the risk of TD. ${ }^{63}$ Another potential preventative strategy is treatment of psychiatric disorders through selective agonism of the trace amineassociated receptor 1 (TAAR1), an approach that has recently been shown to improve symptoms of schizophrenia in adults and does not induce motor abnormalities in animal models. ${ }^{64}$ Targeting the muscarinic system with a combination of xanomeline and trospium has also been proposed as a nondopaminergic strategy for mitigating TD risk. ${ }^{65,66}$

\section{Current Therapeutic Strategies for TD in Older Patients}

The first step in developing the optimal treatment strategy for TD is timely diagnosis, which requires the clinician to be routinely vigilant. ${ }^{67}$ Diagnosis is based on history of exposure to DRBAs, and a minimum duration of only 1 month of AP exposure is required to diagnose TD in individuals aged $\geq 60$ years, compared with 3 months in younger adults. . $^{27,60}$

An early strategy to mitigate TD symptoms involves modification of the existing AP medication regimen if clinically feasible. ${ }^{68}$ However, success with this approach is often limited. ${ }^{23,68,69}$ Two vesicular monoamine transporter 2 (VMAT2) inhibitors, valbenazine and deutetrabenazine, have been approved by the US FDA to treat $\mathrm{TD}^{68,70,71}$ Recent guidelines for the treatment of schizophrenia recommend VMAT2 inhibitors as firstline therapy for patients who have moderate to severe or disabling TD or for patients with mild TD on the basis of such factors as patient preference, associated impairment, or effect on psychosocial functioning. ${ }^{72}$ In two recent studies of subjects aged $\geq 55$ years who had participated in clinical trials conducted by the manufacturer, Sajatovic et al demonstrated that valbenazine (median: 61 years, range: 55-84 years) and 
deutetrabenazine (mean age: 63.1 years, range: 55-81 years are well tolerated in older individuals. ${ }^{73,74}$ Of note, VMAT2 inhibition manages the symptoms of TD but does not cure them; dyskinetic movements generally return when the VMAT2 inhibitor is discontinued. ${ }^{75}$

Although anticholinergic agents may effectively treat acute drug-induced parkinsonism, these medications can worsen TD. ${ }^{23}$ Anticholinergic drug burden is also associated with impaired cognition. Discontinuation of anticholinergic medication leads to an improvement of TD symptoms in approximately $60 \%$ of people, and if enacted, should be done gradually. ${ }^{23,76}$ An additional benefit from deprescribing anticholinergic medication would be a lessening of the memory impairment and other anticholinergic adverse effects associated with this class of drug. ${ }^{77}$

Avoiding TD by eliminating exposure to DRBAs may be the best option for older persons. Several novel agents are being studied for their antipsychotic properties. Alternative mechanisms, including serotonin inverse agonism/antagonism in the absence of dopamine receptor blockade, agonism of TAAR1 receptors, and modulation of muscarinic cholinergic receptors, may provide different therapeutic approaches for patients who require a medication with an AP effect and avoid contributing to the risk of developing TD. ${ }^{63-66}$

\section{Conclusion}

TD is a particular concern for elderly individuals treated with DRBAs, including second-generation APs. The prevalence of TD in this population is up to 5 to 6 times that of younger people and is encountered clinically in part because of the off-label prescription of APs for dementiarelated behavioral and psychological disorders. ${ }^{7,11}$ In addition to the TD symptoms themselves, older people may be more severely impacted by associated comorbidities and impaired physical and mental health. ${ }^{13-15,78}$

Although the recent approval of VMAT2 inhibitors provides a new therapeutic option once TD occurs, avoiding this often irreversible movement disorder would be preferred. An important strategy for mitigating TD risk is prescribing APs that address psychiatric conditions while minimizing the risk of developing this disorder. Currently, second-generation APs are recommended over first-generation APs. ${ }^{23}$ However, the risk of TD among older individuals persists at a rate of approximately $6 \%$ with use of second-generation APs. ${ }^{36}$ Newer APs that are effective in treating mental health disorders but that do not block postsynaptic dopamine D2 receptors in the dorsal striatum, and thus do not carry a significant risk for $\mathrm{TD}$, are needed.

\section{Abbreviations}

APs, antipsychotics; DRBAs, dopamine receptor-blocking agents; FDA, Food and Drug Administration; TD, tardive dyskinesia; VMAT2, vesicular monoamine transporter 2.

\section{Acknowledgments}

Medical writing support for the development of this manuscript, under the direction of the authors, was provided by Sarah Marshall, PhD, of Ashfield MedComms, an Ashfield Health company, and Dena McWain (Ashfield MedComms) copyedited and styled the manuscript per journal requirements.

\section{Author Contributions}

All authors made a significant contribution to the work reported, whether that is in the conception, study design, execution, acquisition of data, analysis and interpretation, or in all these areas; took part in drafting, revising or critically reviewing the article; gave final approval of the version to be published; have agreed on the journal to which the article has been submitted; and agree to be accountable for all aspects of the work.

\section{Funding}

Acadia Pharmaceuticals Inc., San Diego, CA, provided funding for medical writing and editorial support in the development of this manuscript.

\section{Disclosure}

Leslie Citrome: In the past 12 months, consultant: AbbVie, Acadia, Alkermes, Allergan, Angelini, Astellas, Avanir, Axsome, BioXcel, Boehringer Ingelheim, Cadent Therapeutics, Eisai, Impel, Intra-Cellular Therapies, Janssen, Karuna, Lundbeck, Lyndra, Medavante-ProPhase, Merck, Neurocrine, Noven, Otsuka, Ovid, Relmada, Sage, Sunovion, Teva, University of Arizona, and one-off ad hoc consulting for individuals/entities conducting marketing, commercial, or scientific scoping research; Speaker: AbbVie, Acadia, Alkermes, Allergan, Angelini, Eisai, Intra-Cellular Therapies, Janssen, Lundbeck, Neurocrine, Noven, Otsuka, Sunovion, Takeda, Teva, and CME activities organized by medical education companies such as Medscape, NACCME, NEI, Vindico, and universities and professional organizations/ societies; Stocks (small number of shares of common stock): Bristol-Myers Squibb, Eli Lilly, J \& J, Merck, Pfizer 
purchased >10 years ago; Royalties: Wiley (Editor-in-Chief, International Journal of Clinical Practice, through 2019), UpToDate (reviewer), Springer Healthcare (book), Elsevier (Topic Editor, Psychiatry, Clinical Therapeutics).

Stuart H. Isaacson: Honoraria for continuing medical education, consultancy, research grants, and/or promotional speaker on behalf of AbbVie, Acadia Pharmaceuticals, Acorda Therapeutics, Adamas, Addex Therapeutics, AFFiRiS, Alexza Pharmaceuticals, Allergan, Amarantus BioScience, Amneal Pharmaceuticals, Aptinyx, Axial, Axovant Gene Therapies, BenevolentAI, Biogen, Biohaven, Britannia Pharmaceuticals, Bukwang, Cadent, Cala Health, Centogene, Cerecor, Cerevance, Cerevel Therapeutics, Cipla, Eli Lilly, Enterin, GE Healthcare, Global Kinetics, Impel, Intec Pharma, Ipsen, IR Labs, Jazz Pharmaceuticals, Kyowa Kirin, Lundbeck, Merz, Michael J. Fox Foundation, Mitsubishi Tanabe Pharma America, Neuraly, Neurocrine Biosciences, NeuroDerm, Novartis, Parkinson Study Group, Pharma Two B, Prilenia, Promentis Pharmaceuticals, Revance, Roche, Sage, Sanofi, Scion Neurostim, Stoparkinson, Sunovion Pharmaceuticals Inc., Sun Pharma, Supernus, Teva Pharmaceuticals, Theravance Biopharma, UCB, and Zambon.

Danielle Larson: Consulting for Acadia Pharmaceuticals.

Daniel Kremens: Compensation for consulting/speakers' bureau from Teva Pharmaceuticals, Sunovion, Amneal, Lundbeck, Acadia Pharmaceuticals, USWorldMeds, Supernus, Adamas, AbbVie, Merz, Allergan, Acorda, Kyowa Kirin, Neurocrine, and Britannia; research support from Voyager Therapeutics and Revance. The authors report no other conflicts of interest in this work.

\section{References}

1. Rao AS, Camilleri M. Review article: metoclopramide and tardive dyskinesia. Aliment Pharmacol Ther. 2010;31(1):11-19. doi:10.1111/ j.1365-2036.2009.04189.x

2. American Psychiatric Association. Diagnostic and Statistical Manual of Mental Disorders. 5th ed. Arlingtion, VA: American Psychiatric Association; 2013.

3. McEvoy J, Gandhi SK, Rizio AA, et al. Effect of tardive dyskinesia on quality of life in patients with bipolar disorder, major depressive disorder, and schizophrenia. Qual Life Res. 2019;28(12):3303-3312. doi:10.1007/s11136-019-02269-8

4. Cornett EM, Novitch M, Kaye AD, Kata V, Kaye AM. Medicationinduced tardive dyskinesia: a review and update. Ochsner J. 2017;17 (2): $162-174$.

5. Woods SW, Morgenstern H, Saksa JR, et al. Incidence of tardive dyskinesia with atypical versus conventional antipsychotic medications: a prospective cohort study. J Clin Psychiatry. 2010;71 (4):463-474. doi:10.4088/JCP.07m03890yel
6. Correll CU, Leucht S, Kane JM. Lower risk for tardive dyskinesia associated with second-generation antipsychotics: a systematic review of 1-year studies. Am J Psychiatry. 2004;161(3):414-425. doi:10.1176/appi.ajp.161.3.414

7. Jeste DV. Tardive dyskinesia in older patients. J Clin Psychiatry. 2000;61(Suppl 4):27-32.

8. Carton L, Cottencin O, Lapeyre-Mestre M, et al. Off-label prescribing of antipsychotics in adults, children and elderly individuals: a systematic review of recent prescription trends. Curr Pharm Des. 2015;21(23):3280-3297. doi:10.2174/13816128216 66150619092903

9. Citrome L, Kalsekar I, Guo Z, Laubmeier K, Hebden T. Diagnoses associated with use of atypical antipsychotics in a commercial health plan: a claims database analysis. Clin Ther. 2013;35(12):1867-1875. doi:10.1016/j.clinthera.2013.09.006

10. Alexander GC, Gallagher SA, Mascola A, Moloney RM, Stafford RS. Increasing off-label use of antipsychotic medications in the United States, 1995-2008. Pharmacoepidemiol Drug Saf. 2011;20(2):177-184. doi:10.1002/pds.2082

11. Steinberg M, Lyketsos CG. Atypical antipsychotic use in patients with dementia: managing safety concerns. Am J Psychiatry. 2012;169(9):900-906. doi:10.1176/appi.ajp.2012.12030342

12. Caroff SN, Leong SH, Roberts C, Berkowitz RM, Campbell EC. Cumulative burden of illness in veterans with tardive dyskinesia and serious mental disorders. J Clin Psychopharmacol. 2020;40 (1):38-45. doi:10.1097/JCP.0000000000001142

13. Patel RS, Mansuri Z, Chopra A. Analysis of risk factors and outcomes in psychiatric inpatients with tardive dyskinesia: a nationwide case-control study. Heliyon. 2019;5(5):e01745. doi:10.1016/j.heliyon.2019.e01745

14. Waln O, Jankovic J. An update on tardive dyskinesia: from phenomenology to treatment. Tremor Other Hyperkinet Mov (N Y). 2013;3. doi:10.7916/D88P5Z71

15. Loughlin AM, Lin N, Abler V, Carroll B. Tardive dyskinesia among patients using antipsychotic medications in customary clinical care in the United States. PLoS One. 2019;14(6):e0216044. doi:10.1371/ journal.pone.0216044

16. Jeste DV. Tardive dyskinesia rates with atypical antipsychotics in older adults. J Clin Psychiatry. 2004;65(Suppl 9):21-24.

17. Jain R, Correll CU. Tardive dyskinesia: recognition, patient assessment, and differential diagnosis. J Clin Psychiatry. 2018;79(2):16-23. doi:10.4088/JCP.nu17034ah1c

18. Divac N, Prostran M, Jakovcevski I, Cerovac N. Second-generation antipsychotics and extrapyramidal adverse effects. Biomed Res Int. 2014;2014:656370. doi:10.1155/2014/656370

19. Pandey S. Orofacial dyskinesia in elderly. Mov Disord Clin Pract. 2015;2(4):442. doi:10.1002/mdc3.12192

20. Kuo SH, Jankovic J. Tardive gait. Clin Neurol Neurosurg. 2008;110 (2):198-201. doi:10.1016/j.clineuro.2007.09.013

21. Caroff SN, Yeomans K, Lenderking WR, et al. RE-KINECT: a prospective study of the presence and healthcare burden of tardive dyskinesia in clinical practice settings. $J$ Clin Psychopharmacol. 2020;40(3):259-268. doi:10.1097/JCP.0000000000001201

22. Carroll B, Irwin DE. Health care resource utilization and costs for patients with tardive dyskinesia. J Manag Care Spec Pharm. 2019;25 (7):810-816.

23. Ward KM, Citrome L. Antipsychotic-related movement disorders: drug-induced parkinsonism vs. tardive dyskinesia-key differences in pathophysiology and clinical management. Neurol Ther. 2018;7 (2):233-248. doi:10.1007/s40120-018-0105-0

24. Chong SA, Mahendran R, Machin D, Chua HC, Parker G, Kane J. Tardive dyskinesia among Chinese and Malay patients with schizophrenia. J Clin Psychopharmacol. 2002;22(1):26-30. doi:10.1097/00004714-200202000-00005 
25. Caroff SN, Ungvari GS, Cunningham Owens DG. Historical perspectives on tardive dyskinesia. J Neurol Sci. 2018;389:4-9. doi:10.1016/ j.jns.2018.02.015

26. Yassa R, Jones BD. Complications of tardive dyskinesia: a review. Psychosomatics. 1985;26(4):305-307, 310, 312-313. doi:10.1016/ S0033-3182(85)72863-0

27. Kane JM, Smith JM. Tardive dyskinesia: prevalence and risk factors, 1959 to 1979. Arch Gen Psychiatry. 1982;39(4):473-481. doi:10.1001/archpsyc.1982.04290040069010

28. Carbon M, Hsieh CH, Kane JM, Correll CU. Tardive dyskinesia prevalence in the period of second-generation antipsychotic use: a meta-analysis. J Clin Psychiatry. 2017;78(3):e264-e278. doi:10.4088/JCP.16r10832

29. Correll CU, Schenk EM. Tardive dyskinesia and new antipsychotics. Curr Opin Psychiatry. 2008;21(2):151-156. doi:10.1097/ YCO.0b013e3282f53132

30. Solmi M, Pigato G, Kane JM, Correll CU. Treatment of tardive dyskinesia with VMAT-2 inhibitors: a systematic review and meta-analysis of randomized controlled trials. Drug Des Devel Ther. 2018;12:1215-1238. doi:10.2147/DDDT.S133205

31. Patterson-Lomba O, Ayyagari R, Carroll B. Risk assessment and prediction of TD incidence in psychiatric patients taking concomitan antipsychotics: a retrospective data analysis. BMC Neurol. 2019;19 (1):174. doi:10.1186/s12883-019-1385-4

32. Tenback DE, Bakker PR, van Harten PN. [Risk factors for tardive movement disorders in schizophrenia]. Tijdschr Psychiatr. 2015;57 (2):120-124. Dutch.

33. Solmi M, Pigato G, Kane JM, Correll CU. Clinical risk factors for the development of tardive dyskinesia. J Neurol Sci. 2018;389:21-27. doi:10.1016/j.jns.2018.02.012

34. Vardar MK, Ceylan ME, Unsalver BO. Assessment of risk factors for tardive dyskinesia. Psychopharmacol Bull. 2020;50(3):36-46.

35. Woerner MG, Alvir JM, Saltz BL, Lieberman JA, Kane JM. Prospective study of tardive dyskinesia in the elderly: rates and risk factors. Am J Psychiatry. 1998;155(11):1521-1528. doi:10.1176/ ajp.155.11.1521

36. Woerner MG, Correll CU, Alvir JM, Greenwald B, Delman H, Kane JM. Incidence of tardive dyskinesia with risperidone or olanzapine in the elderly: results from a 2-year, prospective study in antipsychotic-naive patients. Neuropsychopharmacology. 2011;36 (8):1738-1746. doi:10.1038/npp.2011.55

37. Jeste DV, Okamoto A, Napolitano J, Kane JM, Martinez RA. Low incidence of persistent tardive dyskinesia in elderly patients with dementia treated with risperidone. Am J Psychiatry. 2000;157 (7):1150-1155. doi:10.1176/appi.ajp.157.7.1150

38. Vieta E, Goikolea JM, Corbella B, et al. Risperidone safety and efficacy in the treatment of bipolar and schizoaffective disorders: results from a 6-month, multicenter, open study. J Clin Psychiatry. 2001;62(10):818-825. doi:10.4088/JCP.v62n1011

39. Purdon SE, Jones BD, Stip E, et al. Neuropsychological change in early phase schizophrenia during 12 months of treatment with olanzapine, risperidone, or haloperidol. The Canadian Collaborative Group for research in schizophrenia. Arch Gen Psychiatry. 2000;57 (3):249-258. doi:10.1001/archpsyc.57.3.249

40. Estevez-Fraga C, Zeun P, Lopez-Sendon Moreno JL. Current methods for the treatment and prevention of drug-induced parkinsonism and tardive dyskinesia in the elderly. Drugs Aging. 2018;35 (11):959-971. doi:10.1007/s40266-018-0590-y

41. Crystal S, Olfson M, Huang C, Pincus H, Gerhard T. Broadened use of atypical antipsychotics: safety, effectiveness, and policy challenges. Health Aff (Millwood). 2009;28(5):w770-w781. doi:10.1377/hlthaff.28.5.w770

42. Kamble P, Sherer J, Chen H, Aparasu R. Off-label use of second-generation antipsychotic agents among elderly nursing home residents. Psychiatr Serv. 2010;61(2):130-136. doi:10.1176/ ps.2010.61.2.130
43. Maust DT, Kim HM, Chiang C, Kales HC. Association of the Centers for Medicare \& Medicaid Services' National Partnership to Improve Dementia Care with the use of antipsychotics and other psychotropics in long-term care in the United States from 2009 to 2014. JAMA Intern Med. 2018;178(5):640-647. doi:10.1001/jamainternmed.20 18.0379

44. Maust DT, Strominger J, Bynum JPW, et al. Prevalence of psychotropic and opioid prescription fills among community-dwelling older adults with dementia in the US. JAMA. 2020;324(7):706-708. doi:10.1001/jama.2020.8519

45. Centers for Medicare and Medicaid Services. Atypical antipsychotic medications: use in adults [fact sheet]. Services UDoHaH, ed. US Department of Health and Human Services; 2015. Available from: https://www.cms.gov/Medicare-MedicaidCoordination/Fraud-Prevention/Medicaid-Integrity-Education /Pharmacy-Education-Materials/Downloads/atyp-antipsych-adultfactsheet11-14.pdf. Accessed September 24, 2021.

46. Yassa R, Lal S. Respiratory irregularity and tardive dyskinesia. A prevalence study. Acta Psychiatr Scand. 1986;73(5):506-510. doi:10.1111/j.1600-0447.1986.tb02717.x

47. Blanchet PJ, Popovici R, Guitard F, Rompre PH, Lamarche C, Lavigne GJ. Pain and denture condition in edentulous orodyskinesia: comparisons with tardive dyskinesia and control subjects. Mov Disord. 2008;23(13):1837-1842. doi:10.1002/mds.22102

48. Godlee FN, Brooks DJ, Impallomeni M. Dyskinesia in the elderly presenting as respiratory disorder. Postgrad Med J. 1989;65 (769):830-831. doi:10.1136/pgmj.65.769.830

49. Klawans HL Jr, Rubovits R. An experimental model of tardive dyskinesia. J Neural Transm. 1972;33(3):235-246. doi:10.1007/ BF01245320

50. Tarsy D, Baldessarini RJ. Pharmacologically induced behavioural supersensitivity to apomorphine. Nat New Biol. 1973;245 (148):262-263. doi:10.1038/newbio245262a0

51. Stegmayer K, Walther S, van Harten P. Tardive dyskinesia associated with atypical antipsychotics: prevalence, mechanisms and management strategies. CNS Drugs. 2018;32(2):135-147. doi:10.1007/ s40263-018-0494-8

52. Stahl SM. Neuronal traffic signals in tardive dyskinesia: not enough "stop" in the motor striatum. CNS Spectr. 2017;22(6):427-434. doi:10.1017/S109285291700061X

53. Fedorenko OY, Loonen AJ, Lang F, et al. Association study indicates a protective role of phosphatidylinositol-4-phosphate-5-kinase against tardive dyskinesia. Int J Neuropsychopharmacol. 2015;18 (6):pyu098. doi:10.1093/ijnp/pyu098

54. Basile VS, Masellis M, Badri F, et al. Association of the MscI polymorphism of the dopamine D3 receptor gene with tardive dyskinesia in schizophrenia. Neuropsychopharmacology. 1999;21 (1):17-27. doi:10.1016/S0893-133X(98)00114-6

55. MacNeil RR, Muller DJ. Genetics of common antipsychotic-induced adverse effects. Mol Neuropsychiatry. 2016;2(2):61-78. doi:10.1159/ 000445802

56. Meltzer HY. The role of serotonin in antipsychotic drug action. Neuropsychopharmacology. 1999;21(2 Suppl):106s-115s. doi:10.1016/S0893-133X(99)00046-9

57. Kapur S, Seeman P. Does fast dissociation from the dopamine d(2) receptor explain the action of atypical antipsychotics?: A new hypothesis. $\mathrm{Am}$ J Psychiatry. 2001;158(3):360-369. doi:10.1176/appi.ajp.158.3.360

58. Yu T, Li Y, Fan F, et al. Decreased gray matter volume of cuneus and lingual gyrus in schizophrenia patients with tardive dyskinesia is associated with abnormal involuntary movement. Sci Rep. 2018;8 (1):12884. doi:10.1038/s41598-018-31186-y

59. Yu T, Li Y, Li N, et al. Abnormal functional connectivity of motor circuit in the schizophrenic patients with tardive dyskinesia: a resting-state fMRI study. Neurosci Lett. 2021;742:135548. doi:10.1016/j.neulet.2020.135548 
60. Caroff SN. Overcoming barriers to effective management of tardive dyskinesia. Neuropsychiatr Dis Treat. 2019;15:785-794. doi:10.2147/NDT.S196541

61. Salem H, Pigott T, Zhang XY, Zeni CP, Teixeira AL. Antipsychoticinduced Tardive dyskinesia: from biological basis to clinical management. Expert Rev Neurother. 2017;17(9):883-894. doi:10.1080/14737175.2017.1361322

62. Street JS, Clark WS, Gannon KS, et al. Olanzapine treatment of psychotic and behavioral symptoms in patients with Alzheimer disease in nursing care facilities: a double-blind, randomized, placebo-controlled trial. The HGEU Study Group. Arch Gen Psychiatry. 2000;57(10):968-976. doi:10.1001/archpsyc.57.10.968

63. Davis J, Zamora D, Horowitz M, Leucht S. Evaluating pimavanserin as a treatment for psychiatric disorders: A pharmacological property in search of an indication. Expert Opin Pharmacother. 2021;22 (13):1651-1660. doi:10.1080/14656566.2021.1942455

64. Koblan KS, Kent J, Hopkins SC, et al. A non-D2-receptor-binding drug for the treatment of schizophrenia. $N$ Engl $J$ Med. 2020;382(16):1497-1506. doi:10.1056/NEJMoa1911772

65. Dean B, Scarr E. Muscarinic M1 and M4 receptors: hypothesis driven drug development for schizophrenia. Psychiatry Res. 2020;288:112989. doi:10.1016/j.psychres.2020.112989

66. Brannan SK, Sawchak S, Miller AC, Lieberman JA, Paul SM, Breier A. Muscarinic cholinergic receptor agonist and peripheral antagonist for schizophrenia. N Engl J Med. 2021;384(8):717-726. doi:10.1056/NEJMoa2017015

67. Citrome L. Clinical management of tardive dyskinesia: five steps to success. $J$ Neurol Sci. 2017;383:199-204. doi:10.1016/j. jns.2017.11.019

68. Ricciardi L, Pringsheim T, Barnes TRE, et al. Treatment recommendations for tardive dyskinesia. Can J Psychiatry. 2019;64 (6):388-399. doi:10.1177/0706743719828968

69. Bergman H, Rathbone J, Agarwal V, Soares-Weiser K. Antipsychotic reduction and/or cessation and antipsychotics as specific treatments for tardive dyskinesia. Cochrane Database Syst Rev. 2018;2018(2): CD000459.
70. Fernandez HH, Stamler D, Davis MD, et al. Long-term safety and efficacy of deutetrabenazine for the treatment of tardive dyskinesia. J Neurol Neurosurg Psychiatry. 2019;90(12):1317-1323.

71. Niemann N, Jankovic J. Treatment of tardive dyskinesia: a general overview with focus on the vesicular monoamine transporter 2 inhibitors. Drugs. 2018;78(5):525-541. doi:10.1007/s40265-0180874-x

72. Keepers GA, Fochtmann LJ, Anzia JM, et al. The American psychiatric association practice guideline for the treatment of patients with schizophrenia. Am J Psychiatry. 2020;177(9):868-872. doi:10.1176/ appi.ajp.2020.177901

73. Sajatovic M, Alexopoulos G, Burke J, Farahmand K, Siegert S. The effects of valbenazine on tardive dyskinesia in older and younger patients. Int $J$ Geriatr Psychiatry. 2020;35:69-79. doi:10.1002/ gps.5218

74. Sajatovic M, Wilhelm A, Finkbeiner S, et al. Long-term safety and efficacy of deutetrabenazine in younger and older patients with tardive dyskinesia. CNS Spectr. 2021;26(2):157-158. doi:10.1017/ S1092852920002527

75. Touma KTB, Scarff JR. Valbenazine and deutetrabenazine for tardive dyskinesia. Innov Clin Neurosci. 2018;15(5-6):13-16.

76. Lerner PP, Miodownik C, Lerner V. Tardive dyskinesia (syndrome): current concept and modern approaches to its management. Psychiatry Clin Neurosci. 2015;69(6):321-334. doi:10.1111/ pcn. 12270

77. Lupu AM, MacCamy KL, Gannon JM, Brar JS, Chengappa KNR. Less is more: deprescribing anticholinergic medications in persons with severe mental illness. Ann Clin Psychiatry. 2021;33(2):80-92.

78. McEvoy J, Park T, Schilling T, Terasawa E, Ayyagari R, Carroll B. The burden of tardive dyskinesia secondary to antipsychotic medication use among patients with mental disorders. Curr Med Res Opin. 2019;35(7):1205-1214. doi:10.1080/03007995.2019.1569871
Neuropsychiatric Disease and Treatment

\section{Publish your work in this journal}

Neuropsychiatric Disease and Treatment is an international, peerreviewed journal of clinical therapeutics and pharmacology focusing on concise rapid reporting of clinical or pre-clinical studies on a range of neuropsychiatric and neurological disorders. This journal is indexed on PubMed Central, the 'PsycINFO' database and CAS, and

\section{Dovepress}

is the official journal of The International Neuropsychiatric Association (INA). The manuscript management system is completely online and includes a very quick and fair peer-review system, which is all easy to use. Visit http://www.dovepress.com/testimonials.php to read real quotes from published authors. 